\title{
La noción de justicia en la crítica benjaminiana del conocimiento
}

\author{
Gisela Catanzaro ${ }^{1}$
}

Abstract

The reference to "justice", persistent in Walter Benjamin's thought, appears to play a double role in his writings. On one hand, it seems to have a gnoseological value -as in the "Epistemo-Critical Prologue" to TheOrigin of German Tragic Drama- in so far it allows the critique of the predominant notion of knowledge as discovery. On the other hand, it seems to have a more political meaning, associated to the interruption of social violence, as in "Critique of violence" where "justice" is opposed to the violence of Myth, perpetuated by Law. Nevertheless, being no other than that same social violence what -in Benjamin's view- expresses and reproduces itself in the methods of discovery, appropriation and codification developed by Science, those two "values" of justice can barely be differentiated or defined on their own in his writings. Bearing this in mind, in the first and second sections of this article we focus on the idea of justice and interpret its protagonism in Benjamin's thought as a shift with respect to the categories privileged by political Theory and Philosophy -in particular: the notion of freedom -, and in association with terms which had been almost excluded from the vocabularies of modern political thought, such as the idea of happiness. Finally, we explore some of the alternative images of knowledge that, through a reference to justice, Benjamin provides in his last writings.

Key-words:W. Benjamin, justice, knowledge, happiness, critique

\footnotetext{
${ }^{1}$ Gisela Catanzaro é doutora em Ciencias Sociales por la Universidad de Buenos Aires, Argentina. Investigadora asistente de CONICET - IIGG
} 


\section{La noción de justicia en la crítica benjaminiana del conocimiento}

\section{1- La lengua de la Ciencia, la lengua del Derecho y la lengua de la Justicia}

"Redención" es una categoría persistente en el pensamiento de Walter Benjamin, donde se asocia no sólo a una peculiar comprensión de la práctica política, sino también, y al mismo tiempo, a una singular representación del conocimiento. En esa representación de un "conocimiento redentor", se trama fundamentalmente la crítica de la definición dominante del método como instancia de aseguración de la verdad y medio de acceso a una materialidad aferrable y en disponibilidad. Pero, por ejemplo en su libro sobre el Trauerspiel, Benjamin dispone, además, algunos de los elementos que se asociarían a un tal "conocimiento redentor". Entre ellos aparece la noción de justicia: "la verdad no es un develamiento que anula el secreto sino una revelación que le hace justicia", y la "justicia" es inconmensurable con la administración de los cuerpos, de todos los cuerpos: cuerpos vivientes, cuerpos caducos, cuerpos muertos, cuerpos-textos y cuerposobjetos.

El derecho -o la lengua de la ley- es, en "Para una crítica de la violencia", precisamente el ejercicio de esa práctica administrativa sobre los cuerpos vivientes. Es un tipo de violencia que se ejerce sobre la vida por causa del derecho mismo y no de lo viviente ${ }^{3}$; o, dicho de otro modo, es esa lengua que sólo puede hablar de lo viviente en tanto aferrable, disponible y ubicable, en tanto decodificable. De allí que la vida de la que habla la lengua de la ley sea necesariamente una "mera" o "nuda" vida: se trata de una vida que ya no tiene secreto para el código, y ese "ya no" alberga el

\footnotetext{
${ }^{2}$ BENJAMIN, Walter. El origen del drama barroco alemán. Madrid: Taurus, 1990, p. 13

3 "La violencia mítica es violencia sangrienta [que se ejerce] sobre la mera vida por causa de ella [misma], la pura violencia divina lo es sobre toda vida por causa del viviente. La primera exige sacrificios, la segunda los acepta." BENJAMIN, Walter: "Para una crítica de la violencia". El texto fue publicado en español por Taurus en Iluminaciones IV. Aquí seguimos, sin embargo, la traducción propuesta por Pablo Oyarzún en BENJAMIN, Walter. Para una crítica de la violencia. Santiago de Chile: Metales pesados, 2008.
} 
sentido de una resistencia vencida. La lengua de la ley sólo puede hablar de una vida cuando las resistencias que su complejidad plantea a su decodificabilidad plena por el código legal han sido vencidas; habla -como la ciencia- de una vida cuyo secreto ha sido anulado mediante una operación de develamiento tras la cual sólo queda la transparencia de un cuerpo desnudo.

Mientras el derecho y la ciencia hablan de una resistencia vencida y de una cierta violencia ejercida sobre los cuerpos, a la posibilidad de justicia queda asociada, por el contrario, en la lectura benjaminiana, la verdad. Dicho con términos que tomamos prestados en parte a Pablo Oyarzún ${ }^{4}$ : para Benjamin, sólo un conocimiento que haga justicia a lo conocido, y no uno que se conforme con la mera administración de un "corpus" ordenable en conceptos universales preestablecidos, puede reclamar para sí la verdad. Pero ésta, la verdad, a diferencia de lo que pretende el historicismo en su intento de hacer justicia a lo singular, tampoco es "a aferrar"; se trata, más bien, de cuidar amorosamente el espacio para que pueda aparecer, lo cual exige paciencia e implica a menudo los tiempos largos, morosos, del rodeo. En la expresión "la verdad no ha de escapársenos" proveniente de Gottfried Keller, Benjamin lee un lema en el que el historicismo manifiesta su confianza en la accesibilidad de una verdad pasiva y dada "que espera", a la llegada del investigador casto, $y$, junto con esa confianza, manifiesta su positivismo profundo, su solidaridad última con la violencia ejercida por la posición universalista abstracta.

De este modo, los textos de Benjamin parecen indicar una otra vez en la misma dirección: la justicia, su lengua, no debe ser confundida con el derecho o la ciencia; no debe ser confundido el modo justo de nombrar la vida, con la decodificabilidad de la vida operada por el código científico-

\footnotetext{
${ }^{4}$ OYARZÚN ROBLES, Pablo. "Cuatro señas sobre experiencia, historia y facticidad”, en BENJAMIN, Walter. La dialéctica en suspenso. Santiago de Chile: ARCIS-LOM, 1996.

5 BENJAMIN, Walter. "Sobre el concepto de historia" en La dialéctica en suspenso. Santiago de Chile: ARCIS-LOM, 1996, p. 50.
} 
legal. La lengua del derecho, o la de la ciencia, y la de la justicia resultan inconmensurables. Pero, ¿cuál sería esa "lengua de la justicia"? ¿Disponemos - dispone Benjamin- de ella? Si el historicismo es -a pesar de las apariencias- positivista, y -siéndolo- es violento, ese positivismo no se juega sólo en su culto científico de la facticidad, sino también -y sobre todoen su creencia en la existencia, en el carácter ya dado y disponible, de una lengua que diga plenamente la justicia y la verdad.

En efecto, si hay algo en lo que a nuestro entender Benjamin insiste ${ }^{6}$ a lo largo de toda su vida, es en la no disponibilidad tanto de la verdad como de esa lengua-otra de la justicia, de la cual sólo tenemos retazos ${ }^{7}$. Es enfatizando dicha no disponibilidad de la verdad frente al lema historicista de una verdad "a apresar" que, en la versión francesa de la quinta tesis sobre el concepto de historia, Benjamin destaca el carácter frágil y fugaz de esa verdad no garantizada, que sólo es presente en la inminencia de su desaparición:

"[l]a verdad inmóvil que no hace más que esperar al investigador no corresponde en absoluto a este concepto de la verdad en materia histórica. Se apoya, más bien en el verso de Dante que dice: es una imagen única, irrecuperable, del pasado que se desvanece con cada presente que no ha sabido reconocerse aludido por ella",

La verdad no está disponible ni espera. O bien: aquello a la mano, diponible y aferrable no es la verdad; y la misma marca de fugacidad, fragmentariedad, de lo siempre amenazado y frágil, y -sobre todo- de lo siempre ajeno, extemporáneo, y no familiar que envuelve a la verdad, es la que caracteriza a las emergencias -que no nos pertenecen y en cambio nos atañen seriamente- de aquella posible lengua de la justicia.

\footnotetext{
${ }^{6}$ Desde el temprano texto sobre el lenguaje ("Sobre el lenguaje en general y sobre el lenguaje de los humanos") y el polémico escrito sobre la violencia ("Para una crítica de la violencia"), hasta las tesis "Sobre el concepto de historia" y el "Libro de los pasajes", pasando por el brevísimo "Fragmento teológico-político".

${ }^{7}$ LÓPEZ, María Pía.: "Minimalismo de la conversación” en Revista Nombres №24, Año XIX. Universidad Nacional de Córdoba.

${ }^{8}$ BENJAMIN, Walter. "Sobre el concepto de historia" en La dialéctica en suspenso. Santiago de Chile: ARCIS-LOM, 1996, p. 50
} 
Pero si esto fuera así, la posición en la crítica que Benjamin busca (re)crear, no podría ser -como a veces se sugiere- la del profeta, aquél que habla la lengua de la justicia, condenando con ella, desde arriba, la miseria del mundo decadente, incapaz de elevarse a altura semejante. La práctica benjaminiana de la crítica no se asemejaría tampoco a la del ángel, que se espanta, alma bella que sabe lo verdadero y lo justo y no puede comprender esa miseria general que se acumula a sus pies. Benjamin no confía -como lo hacen el profeta $y$ el positivista- en disponer de un lenguaje semejante; pero tampoco le basta con la sorpresa del ángel atónito: "El asombro porque las cosas que vivimos sean 'todavía' posibles [...] no está al inicio de un conocimiento", ${ }^{\text {, }}$ señala en sus tesis sobre la historia; y es sin embargo la producción de un tal conocimiento precisamente lo que urge, y lo que sus reflexiones buscan producir $^{10}$. A diferencia del ángel y del cultor del enigma $^{11}$, Benjamin quiere comprender, y para hacerlo construye imágenes, "iluminaciones", "iluminaciones profanas". ${ }^{12}$

\footnotetext{
${ }^{9}$ BENJAMIN, Walter. "Sobre el concepto de historia" en La dialéctica en suspenso. Santiago de Chile: ARCIS-LOM, 1996, p. 53

10 “La tradición de los oprimidos nos enseña que el 'estado de excepción' en el que vivimos es la regla. Tenemos que llegar a un concepto de historia que le corresponda." BENJAMIN, Walter. "Sobre el concepto de historia" en La dialéctica en suspenso. Santiago de Chile: ARCIS-LOM, 1996, p. 53.

${ }^{11}$ El asombro tampoco es crítico en el campo del arte. Así, la estética del poeta “ "en état de surprise', del arte como reacción sorprendida, está presa de algunos prejuicios románticos catastróficos" que es preciso corregir -señalará en su texto sobre el surrealismo-. En lugar de festejar una fantasmagoría y un ocultismo de tiempo libre, para los cuales lo enigmático está siempre circunvalado y lejos, más valdría adoptar "una óptica dialéctica" capaz de percibir "lo cotidiano como impenetrable y lo impenetrable como cotidiano" para hacerlo estallar, para favorecer la disolución de la superficie rigidificada de la realidad.

BENJAMIN, Walter. "El surrealismo. La última instantánea de la inteligencia europea" en Iluminaciones I. Madrid: Taurus, 1980, p. 58.

12 "Subrayar patética o fanáticamente el lado enigmático de lo enigmático, no nos hace avanzar. Más bien penetramos el misterio sólo en el grado en que lo reencontramos en lo cotidiano (...) La investigación apasionada, por ejemplo, de fenómenos telepáticos no nos enseña sobre la lectura (proceso eminentemente telepático) ni la mitad de lo que aprendemos sobre dichos fenómenos por medio de una iluminación profana, esto es, leyendo. O también: la investigación apasionada acerca del fumar haschisch no nos enseña nada sobre el pensamiento (que es un narcótico eminente) ni la mitad de lo que aprendemos sobre el haschisch por medio de una iluminación profana, esto es, pensando." BENJAMIN, Walter. "El surrealismo. La última instantánea de la inteligencia europea" en

Iluminaciones I. Madrid: Taurus, 1980, p. 58-59
} 
El "conocimiento redentor" no es, entonces, el que se dice en la lengua de la justicia. En tanto ya disponible, la lengua de la justicia es sólo divina, no nuestra. A nosotros "no nos es lícito tratar de escribir [la historia] en términos teológicos"13, y es por eso que el conocimiento redentor únicamente podría escribirse en una lengua drásticamente profana y plebeya, que sólo a veces existe, y existe precariamente: una lengua tartamuda. Esa lengua estaría hecha de retazos de historia con los que nos topamos, pero también sería una dispuesta a destrozar las figuras enteras allí donde la solemnidad parezca inmunizarlas contra la experiencia de su propia miseria. ¿A qué percepción se le hace captable esa miseria? Adorno vio que, tal como había sostenido Benjamin, sólo desde la perspectiva de la redención saltaba a la superficie la miseria de un mundo empobrecido que al mismo tiempo- se revelaba como insoportable. Lo vio y lo escribió en el último fragmento de Mínima Moralia, donde también parecería querer corregir a Benjamin:

"El único modo que aún le queda a la filosofía de responsabilizarse a la vista de la desesperación, es intentar ver las cosas tal como aparecen desde la perspectiva de la redención. El conocimiento no tiene otra luz iluminadora del mundo que la que arroja la idea de la redención: todo lo demás se agota en reconstrucciones y se reduce a mera técnica. Es preciso fijar perspectivas en las que el mundo aparezca trastocado, enajenado, mostrando sus grietas y desgarros, menesteroso y deforme en el grado en que aparece bajo la luz mesiánica [...] Pero esta posición representa también lo absolutamente imposible, puesto que presupone una ubicación fuera del círculo mágico de la existencia, aunque sólo sea en un grado mínimo, cuando todo conocimiento posible, para que adquiera validez, no sólo hay que extraerlo primariamente de lo que es, sino que también, y por lo mismo, está afectado por la deformación y la precariedad mismas de las que intenta salir. Cuanto más afanosamente se hermetiza el pensamiento a su ser condicionado en aras de lo incondicionado es cuando más inconciente y, por ende, fatalmente sucumbe al mundo." ${ }^{14}$

Pero ¿se pone la perspectiva benjaminiana "fuera del círculo mágico de la existencia, aunque sólo sea en un grado mínimo”? ¿Fue justo Adorno con Benjamin? ¿O podría pensarse que, siendo injusto con Walter Benjamin, le

\footnotetext{
${ }^{13}$ BENJAMIN, Walter. “'Convoluto N' de La obra de los Pasajes”, en La dialéctica en suspenso. Santiago de Chile: ARCIS-LOM, 1996, p. 81
}

${ }^{14}$ ADORNO, Theodor. Minima Moralia. Madrid: Editora Nacional, 2002, p. 239 
hizo, en cambio, justicia a la idea benjaminiana de que el conocimientootro, la lengua-otra de la justicia, no es la más pura, la más indemne, la que está "bien" parada y se derrama esclarecedoramente sobre los a-lumnos que se arrastran en la oscuridad, sino -al contrario- la más afectada por ese mundo al que querría redimir? La "lengua de la justicia" benjaminiana señalamos- es una lengua afectada de la precariedad, de la fragilidad del mundo; pero también -agregamos ahora- lo suficientemente potente como para evitar hermetizarse, para resistir la tentación de borrar esa fragilidad que la habita con la gimnasia de la autoafirmación, incluso la gimnasia de la autoafirmación del filósofo o del político. Pero si fuera así ¿qué es lo que, por momentos (al menos), parece volver inaudible -para Adorno, pero no sólo para él- esta politicidad débil del pensamiento benjaminiano?

Como posible indicio de esa inaudibilidad, está el empleo -persistente en la obra de Benjamin- del vocabulario teológico: "justicia divina”, "fuerza mesiánica”, "lengua pura y verbo creador”, “redención”. Pero ¿basta este vocabulario a veces absoluto y tajante al que Benjamin nunca renunció para explicar que sus escritos hayan podido ser retraducidos a los términos más habituales de la práctica política, y sus enigmáticas frases interpretadas como consignas transparentes? ${ }^{15}$ La escritura benjaminiana está, también, marcada por ese tono profético que, sobre todo cuando dice "justicia", parece sonar a "va a tronar (¿desde dónde?) el escarmiento”. Si es cierto que la prosa benjaminiana no condena la miseria del mundo circundante desde una posición aérea y a resguardo de la pobreza generalizada, también lo es que el tono profético, mucho más depurado de convencionalismos académicos plebeyisantes que en el caso de Adorno, persiste en toda su obra. $\mathrm{Y}$ es posible que ese insistente tono profético benjaminiano, que parecería condensado y exacerbado en la invocación a la justicia, le reste a su escritura el recuerdo de esa fragilidad y precariedad intramundanas que las imágenes que pueblan su prosa se empeñan en evocar.

\footnotetext{
15 A diferencia de los textos de Adorno, que siempre siguieron resultando indigeribles para cierto activismo inmediatista presuroso por autoafirmarse.
} 
Dicho esto, ¿no convendría reinterrogar esa apelación benjaminiana a "la justicia" que a veces suena tan grave y sentenciosa en sus reflexiones sobre la historia? Eso es precisamente lo que nos proponemos hacer; y lo haremos a partir de un doble movimiento, de una doble relación. Por una parte, la relación -"negativa"- de "la justicia" con una noción central de la filosofía política: "la libertad"; por la otra, la imbricación de esa noción de justicia con una idea "infrecuente" o "menor"16 no sólo en la gran filosofía moderna, sino también en la teoría crítica de la sociedad: la idea de felicidad. ¿Pueden justicia y felicidad ser pensadas por separado? O mejor: su separación ¿no estará preanunciando ya un determinado marco al planteamiento del problema de la historia que es precisamente aquel del cual Benjamin quiere arrancarlo? ¿Y si preguntas como estas, preguntas por la relación entre felicidad y justicia, fueran, más que un mero capricho de la reflexión, las que hoy importan verdaderamente, las que importa que nos hagamos? Lo sospechamos. Para empezar a pensarlas, sin embargo, es preciso un movimiento previo no exento de peligro y al que también nos inducen las reflexiones benjaminianas: la puesta en suspenso, para su interrogación, del protagonismo que, también en los planteamientos del problema de la historia "más próximos y familiares"17, detenta la categoría de la libertad.

\section{2- Libertad, Justicia y Felicidad}

La "libertad" es la categoría central de las Lecciones sobre la filosofía de la historia universal, que dicta Hegel en 1825. Su concepto señala lo que verdaderamente está en juego en la historia, o, dicho de otro modo, ella constituye el verdadero meollo de ese drama subjetivo que la historia es, y

\footnotetext{
${ }^{16} \mathrm{Al}$ respecto, se puede consultar el interesante libro de Silvia Schwarzböck : Adorno y lo político. Buenos Aires: Prometeo, 2008.

${ }^{17}$ En una carta a Max Horkheimer datada en febrero de 1940, Benjamin le presenta sus reflexiones sobre el concepto de historia como "una primera tentativa de fijar un aspecto de la historia que debe establecer un corte irremediable entre nuestra manera de ver y las sobrevivencias del positivismo que [...] demarcan tan profundamente incluso aquellos conceptos de Historia que, en sí mismos, son para nosotros los más próximos y los más familiares." Citado por Pablo Oyarzún en "Cuatro señas sobre experiencia, historia y facticidad" en BENJAMIN, Walter. La dialéctica en suspenso. Santiago de Chile: ARCIS-LOM, 1996, p. 68.
} 
en el cual el espíritu toma progresiva conciencia de su sustancia. "Así como la gravedad es la sustancia de la materia", dice Hegel,

"es la libertad la sustancia del espíritu. Inmediatamente claro para todos es que el espíritu posee la libertad entre otras propiedades. Pero la filosofía nos enseña que todas las propiedades del espíritu existen sólo mediante la libertad, que todas son simples medios para la libertad [...], que la libertad es la única cosa que tiene verdad en el espíritu" ${ }^{\text {"18 }}$.

Es oponiendo el espíritu a su "perfecto contrario": la materia, como la filosofía enseña que la libertad constituye la naturaleza del espíritu, y, al mismo tiempo, puede aportar las claves para la determinación de ese concepto de libertad. Así, a continuación del pasaje que acabamos de mentar, Hegel señala:

"La materia es pesada por cuanto hay en ella el impulso hacia un centro [...] El espíritu, por el contrario, consiste justamente en tener el centro en sí. Tiende también hacia el centro; pero el centro es él mismo en sí [...] La materia tiene su sustancia fuera de sí. El espíritu, por el contrario, reside en sí mismo; y esto justamente es la libertad. Pues si soy dependiente, me refiero a otra cosa, que no soy yo, y no puedo existir sin esa cosa externa. Soy libre cuando estoy en mí mismo. ${ }^{19}$

De este pasaje, pletórico de consecuencias para la filosofía de la historia, sólo podemos retener ahora un elemento: la ajustadísima imbricación que en él se expone entre libertad e independencia. Ser libre es ser independiente. Mejor dicho, puesto que la independencia no consiste en que el movimiento comience en uno sino fundamentalmente en que uno sea capaz de interrumpir el movimiento (impulsos corporales, influencias del mundo exterior, etc. $)^{20}$, ser libre es conquistar la independencia en relación a las sugerencias de la naturaleza interna y externa, saberse determinado y adquirir cierto poder sobre eso que nos determina, para poder actuar de acuerdo a fines "puestos" y no "dados", fines "propios". Pero, en segundo lugar, y tomando ahora la introducción hegeliana en su conjunto, es preciso destacar que esa máxima aproximación operada por Hegel entre libertad e

\footnotetext{
${ }^{18}$ HEGEL, Georg Wilhelm Friedrich. "Introducción general" en Lecciones sobre la Filosofía de la Historia Universal. Madrid: Alianza, 1999, p. 62.

${ }^{19}$ HEGEL, Georg Wilhelm Friedrich. "Introducción general" en Lecciones sobre la Filosofía de la Historia Universal. Madrid: Alianza, 1999, p. 62.

${ }^{20}$ HEGEL, Georg Wilhelm Friedrich. "Introducción general" en Lecciones sobre la Filosofía de la Historia Universal. Madrid: Alianza, 1999, p. 64.
} 
independencia se da simultáneamente a una separación máxima entre libertad y felicidad, expuesta en su famosa consideración de que los momentos felices son, en la historia, páginas vacías; en su idea de que "la historia no es el terreno de la felicidad". ${ }^{21}$

Si no cabría sostener que la felicidad está ausente, sin más, de las reflexiones hegelianas sobre la historia ${ }^{22}$, sí cabe sospechar que ella no es, para Hegel, lo que verdaderamente cuenta. Y no lo es porque, en sus reflexiones, la historia importa ante todo como ese "Libro" en el que los acontecimientos ingresan como portadores -y aportadores- de sentido, de un sentido que justifica lo que en ellos pudo haber habido de padecimiento, o que -al ser reconocido por el filósofo- nos permite hallar algo valioso e inmortal en esa "maraña" que inmediatamente se presenta como puro padecer. Dicho de otro modo, la felicidad no es lo que importa en la historia que importa, la historia como Libro, porque lo que llena las páginas de esa historia es "el sentido" que habitaba aún en el dolor y en la muerte de los cuerpos, y que no muere con ellos: se trata, antes bien, de lo positivo que trasciende -que persiste tras- lo negativo, y así, "los momentos de felicidad", sidos o no, pero siempre particulares y caducos, no podrían llenar esas páginas que hablan de lo que persiste, de lo que en y a través de la muerte no muere.

Ahora bien, más allá de Hegel, y de las peculiares connotaciones que tiene en su filosofía de la historia la noción de libertad, ${ }^{23}$ esta noción continuó siendo una suerte de eje gravitatorio -aunque no siempre explícito- del problema de la historia en muchos de los autores y obras más ricos y complejos del "materialismo dialéctico". La cuestión de la práctica, y de la determinación del sujeto como producto de cuya acción resulta la historia,

\footnotetext{
21 "Se puede tomar también la felicidad como punto de vista en la consideración de la historia; pero la historia no es el terreno para la felicidad. Las épocas de felicidad son en ella páginas vacías." HEGEL, Georg Wilhelm Friedrich. "Introducción general" en

Lecciones sobre la Filosofía de la Historia Universal. Madrid: Alianza, 1999, p. 88.

${ }^{22}$ Nada lo está, y en eso consiste lo "engullidor" del movimiento hegeliano.

${ }^{23}$ Connotaciones que no cabría -creemos- adjudicar sin más a toda la tradición dialéctica.
} 
cuestión que obsesionó tanto a un Marx como a un Lukàcs, remite en última instancia a ella, aunque de modo negativo, crítico, en -por ejemplo, y valga la redundancia- la crítica de la cosificación desplegada en Historia y conciencia de clase. La cosificación, señala Lukàcs allí, es un estado de la sociedad en el cual los hombres no pueden reconocerse como verdaderos productores de la historia a pesar de haberse afirmado ya como sujetos libres que hacen algo a/con la naturaleza en lugar de asumirla como mero destino impuesto. En sus palabras, cosificado es,

"un estado en el cual los hombres van destruyendo, disolviendo y dejando a sus espaldas las vinculaciones 'naturales' irracionales y fácticas, pero al mismo tiempo levantan con la realidad por ellos mismos creada, 'autoproducida', una especie de segunda naturaleza cuyo decurso se les enfrenta con la misma despiadada necesidad que las viejas fuerzas irracionales de la naturaleza" 24

Pues bien, si indiscutiblemente Benjamin coincidirá con Lukàcs en la necesidad de emanciparse del destino, para él, precisamente en ese círculo mítico del destino, quedará comprendida aquella perdurable representación sacrificial de la historia de impronta hegeliana con la que Lukàcs no termina de romper. Ella postula, primero, a la conciencia de la libertad y a la libertad misma como metas de la dinámica histórica y de la política, para inmediatamente convertirlas en recompensas por un sufrimiento padecido e ineluctable, con el cual -en tanto portador del sentido y momento necesario del advenimiento del fin último- sólo cabría reconciliarnos. Para Benjamin, por el contrario, no se trata de justificar los sacrificios sino de ponerles fin $^{25}$. Por eso, si ya en escritos relativamente tempranos como "Para una crítica de la violencia" insiste en la necesaria crítica del destino, no es en la meta de la "libertad humana" donde buscará hacer pie para "poner término a la violencia mítica" ${ }^{26}$, sino en ideas más o menos anómalas para esta tradición:

\footnotetext{
${ }^{24}$ LUKÀCS, Georg. Historia y conciencia de clase. Madrid: Orbis, 1985, p. 54.

${ }^{25} \mathrm{Al}$ respecto de esta palabra, Pablo Oyarzún, en su traducción de los textos benjaminianos, señala que "Benjamin propone una distinción entre 'meta' (Ziel) y 'fin', 'término' (Ende), acentuando que su concepción de la historia no tiene un carácter teleológico, sino interruptivo." Cfr. BENJAMIN, Walter. "Fragmento teológico-político" en La dialéctica en suspenso. Santiago de Chile: ARCIS-LOM, 1996, p. 181.

${ }^{26}$ BENJAMIN, Walter. Para una crítica de la violencia. Santiago de Chile: Metales pesados, 2008, traducción de Pablo Oyarzún. El texto original en alemán del cual extraemos esta expresión es el siguiente: "Gerade diese Aufgabe legt in letzter Instanz noch einmal die Frage nach einer reinen unmittelbaren Gewalt vor, welche der mythischen
} 
la justicia y la felicidad. Y es esa ruptura en los puntos de partida que deben ser asumidos para imaginar una vida emancipada, la que -a nuestro entender- se anuncia explícitamente en el brevísimo "Fragmento teológicopolítico", datado por algunos en 1920 y por otros en 1938. Allí leemos:

"Sólo el Mesías mismo consuma todo acontecer histórico, y en este sentido: sólo y primeramente él libera, crea la relación de ese [acontecer] con lo mesiánico mismo. Por eso nada histórico puede pretender relacionarse de por sí con lo mesiánico. Por eso el Reino de Dios no es el telos de la dynamis histórica; no puede ser puesto como meta [Ziel]. Históricamente visto no es meta, sino fin [Ende]. Por eso el orden de lo profano no puede construirse sobre el pensamiento del Reino de Dios, por eso la teocracia no tiene sentido político, sino únicamente un sentido religioso [...] El orden de lo profano tiene que erigirse sobre la idea de la felicidad [...] Afanarse en pos de ésta, incluso en aquellos grados del hombre que son naturaleza, es la tarea de la política mundial, cuyo método ha de llamarse nihilismo."27

Como veremos enseguida, Benjamin postula a esa misma felicidad que Hegel había descartado para la historia, menos como una nueva meta en reemplazo de la anterior, que como una idea a la luz de la cual la realidad de la infelicidad actual pudiera emerger en sus más crudos perfiles y desnuda de los atenuantes reconciliadores y dignificantes del sentido. Pero si aquí la felicidad no constituye una nueva meta para la política, sí señala el problema y la tarea que competen a la política, a una política emancipadora, es decir, a una práctica histórica que Benjamin llama a veces también "redentora", a condición de no restar sustancialidad al adjetivo: se trata volvemos a insistir- de una redención profana. Esto es: la felicidad no se relaciona inmediatamente con la Redención. Antes bien, la idea de la felicidad señala precisamente la discontinuidad existente entre dos órdenes: "el Reino" y el "mundo profano", que había sido escamotada en las lecturas religiosas de la historia en las que "el acceso en la inmortalidad" contaba como la meta en pos de la cual se organizaban -y a la luz de la cual

Einhalt zu gebieten vermöchte. "Zur Kritik der Gewalt" in Walter Benjamin Gesammelte Schriften, vol II 1, Suhrkamp, Frankfurt a. M., 1999, S. 179-204. De acuerdo a la traducción de Oyarzún: "Precisamente esta tarea plantea una vez más, en última instancia, la pregunta por una violencia inmediata pura, que pudiese poner término a la violencia mítica."

${ }^{27}$ BENJAMIN, Walter. "Fragmento teológico-político" en La dialéctica en suspenso.

Santiago de Chile: ARCIS-LOM, 1996, p. 181 y 182. 
adquirían sentido- las prácticas profanas. Sin embargo -dice Benjamin-, “nada histórico puede pretender relacionarse de por sí con lo mesiánico”, asî como no constituye un problema, una tarea, de lo mundano "la restitutio in integrum religioso-espiritual que introduce en la inmortalidad" ${ }^{28}$. Entre ambos órdenes -el profano y el divino, la historia y el Reino- hay un abismo. Un abismo cuyo señalamiento no evidencia la pregnancia de cierta nostalgia romántica por un origen perdido en el pensamiento benjaminiano, sino más bien lo complejo de un movimiento que, a la vez, desliga y exige un compromiso: desliga a la política de la causa de la inmortalidad y de sus compromisos con la lógica del sacrificio de los cuerpos en pos de un sentido eterno $^{29}$, y vuelve su atención sobre la causa de lo viviente, caduco y transitorio; sobre aquello que atañe a lo mundano en tanto mundano.

Ese tipo de atención es la que practica -en tanto lector, en tanto intérprete- el mismo Benjamin en innumerables pasajes de su obra; pero la segunda de sus tesis sobre el concepto de historia tal vez constituya, además, uno de los lugares donde más nos aproxima a esa imbricación que mentábamos antes entre la felicidad y una necesaria producción de justicia; entre la felicidad y una redención profana:

"la imagen de la felicidad que cultivamos está teñida de parte a parte por el tiempo al que nos ha remitido de una vez y para siempre el curso de nuestra vida. Una felicidad que pudiera despertar envidia en nosotros la hay sólo en el aire que hemos respirado, en compañía de hombres con quienes hubiésemos podido conversar, de las mujeres que podrían habérsenos entregado. En otras palabras, en la representación de la felicidad oscila inalienablemente la de la redención"30

La felicidad, habíamos sostenido en nuestra lectura del "Fragmento teológico-político", es lo que le compete a la práctica histórica, mundana, profana. Esa felicidad es mentada, en este pasaje, en imágenes, en imágenes

\footnotetext{
${ }^{28}$ BENJAMIN, Walter. "Fragmento teológico-político" en La dialéctica en suspenso. Santiago de Chile: ARCIS-LOM, 1996, p. 181 y 182.(Itálicas en el original)

${ }^{29}$ Para Benjamin se trataría, en todo caso, de la "eternidad de un ocaso" (Cfr. "Fragmento teológico-político").

${ }^{30}$ BENJAMIN, Walter. "Sobre el concepto de historia" en La dialéctica en suspenso. Santiago de Chile: ARCIS-LOM, 1996, p. 48.
} 
corporales: como respiración, compañía, conversación, placer. Son modos de la corporalidad, son cuerpos mundanos, los que aparecen en escena mejor: los que vuelven a la escena de la que habían sido corridos ${ }^{31}$ - con la cuestión de la felicidad; y ambos, la felicidad y lo mundano, están marcados por la transitoriedad. Así como -a pesar de la Historia Universal- no hay hombres inmortales, tampoco hay "La" felicidad más allá del tiempo, sino únicamente en él. Sobre esta marca de transitoriedad que porta la felicidad se detiene -también- Benjamin en este pasaje. Pero que "esté" en el tiempo no indica únicamente, para él, que la felicidad sea temporalmente situable, que haya distintas felicidades posibles para distintas épocas, sino también que la muerte impone un límite rotundo a la felicidad, y, de este modo, parte a esa identidad (ya sea la de la época, la del individuo, u otra) en dos: la felicidad que fue y la que "pudo haber sido".

Pues bien, a esa partición de las identidades, que la Historia monumental nos presenta como figuras a las que, para bien o para mal, no falta nada, a esa partición de las "figuras" de la historia se asocia -queremos sugeriralgo fundamental de aquella posibilidad de "redención profana" y un posible sentido de la justicia en el pensamiento de Benjamin. Ésta última, como señala en su introducción al Origen del drama barroco alemán, no consiste en una anulación del secreto de lo viviente, en un desvelamiento que lo aprende, y lo aprende plenamente como una identidad positiva, sino que se asocia a una revelación de eso viviente también en lo que no se compone con su identidad reconocible. En otros términos, "hacer justicia" a lo mundano en tanto mundano no es aprehenderlo "tal como fue", ni como

\footnotetext{
${ }^{31}$ Unos años antes que Hegel y bastantes después de Fortimbrás, Herder escribía: "Nuestro cuerpo se pudre en el sepulcro y el recuerdo de nuestro nombre pronto palidece y pasa al reino de las sombras; sólo incorporándonos a la voz de Dios, es decir, a la tradición formadora, perdura nuestra acción, aunque anónimamente, en las almas de los nuestros [...] La filosofía de la historia que sigue fielmente la cadena de la tradición, es, por lo tanto, la única verdadera historia de la humanidad, sin la cual todos los acontecimientos externos del mundo no son más que humo o fantasmas espantosos. Horrendo es el aspecto de las revoluciones que amontonaron ruinas sobre ruinas, eternos comienzos sin fin, trastornos del destino sin intención duradera. Sólo la continuidad de la cadena formativa sabe ordenar tantas ruinas en un conjunto donde, si bien desaparecen las figuras humanas, sobrevive victorioso el espíritu de la humanidad." HERDER, Johann Gottfried. Ideas para una Filosofía de la Historia de la Humanidad. Buenos Aires: Losada, 1959, p. 265.
} 
figura, sino producir el lugar para que se revele como algo complejo, como un "campo de fuerzas" ${ }^{32}$, como una "constelación saturada de tensiones", como algo que fue $y$ que no pudo ser, como algo sido, positivo, y algo negativo; o mejor: como algo positivo en tanto sido pero también negativo en tanto trunco y nuevamente "positivo" en tanto deseo, en tanto pendiente.

\section{3- Justificación y justicia interpretativa}

Frente a la "elegante indiferencia por la objetividad" mostrada por el universalismo abstracto, el objetivo de una filosofía de la historia universal concreta consistía -nos enseña Hegel en sus Lecciones- en "justificar la despreciada realidad" atendiendo al "espíritu de los acontecimientos" ${ }^{33}$, atendiendo al fin que, tras el tumulto de superficie, se venía realizando en los acontecimientos y que nos permite comprenderlos como eslabones necesarios de una cadena que llega a nosotros.

A esa idea de justificación contesta la apelación benjaminiana a la justicia. En un sentido cognitivo, ella constituye una pieza clave de su crítica al modo de lectura de la historia que se contenta -como unos años más tarde señalará Levi-Strauss en una sorprendente afinidad con Benjamin- con “enhebrar cronológicamente las dinastías y las guerras al hilo de las racionalizaciones secundarias." ${ }^{34}$ Mientras a este tipo de historiador, escribe Benjamin, "la sucesión de acontecimientos le corr[e] entre los dedos como un rosario", el materialista "no sucumbe más a la representación de que la historia es algo que se deja narrar" ${ }^{35}$; y los hechos, que para aquel

\footnotetext{
32 "La pre-historia y la post-historia de un estado de hechos histórico aparecen en él mismo, en virtud de su exposición dialéctica. Más aún: todo estado de cosas histórico expuesto se polariza y se convierte en un campo de fuerzas en que se juega la confrontación entre su pre-historia y su post-historia." BENJAMIN, Walter. "Convoluto N de La obra de los pasajes" en La dialéctica en suspenso. Santiago de Chile: ARCIS-LOM, 1996, p. 139.

${ }^{33}$ Para esa filosofía o "consideración racional" de la historia lo primero no son las pasiones de los pueblos, "junto a las cuales se empujan los acontecimientos; sino que lo primero es el espíritu de los acontecimientos, que hace surgir los acontecimientos; este es Mercurio, el guía de los pueblos" HEGEL, Georg Wilhelm Friedrich. "Introducción general" en Lecciones sobre la Filosofía de la Historia Universal. Madrid: Alianza, 1999, p. 46.

${ }^{34}$ LEVI-STRAUSS, Claude. "Historia y etnología" en Antropología estructural. Buenos Aires: EUDEBA, 1977, p. 24.

${ }^{35}$ BENJAMIN, Walter. "Apuntes sobre el concepto de historia" en La dialéctica en suspenso. Santiago de Chile: ARCIS-LOM, 1996, p. 106.
} 
constituían el material dócil e inerte de una narración épica, se convierten, para éste, en "algo que acaba de salirl[e] al paso" 36 , en enigmas resistentes, pero también en materialidades sugerentes, que plantean sus propias exigencias al lector ${ }^{37}$ y que es preciso interpretar. "Sólo cuando el decurso histórico se le escurre al historiador por las manos, liso, como un hilo, es lícito hablar de un progreso" -escribe Benjamin- "[p]ero si es un cordón de múltiples fibras, deshilachado en mil greñas, que cuelga como trenza suelta, ninguna de ellas tiene su lugar determinado, mientras no se las recoja a todas y se las entrelace, como un tocado." 38

¿Cómo se muestra la historia en un pasaje como éste? ¿Y qué dice ese mostrarse de la diferencia entre justificación y justicia? Es preciso destacar, en primer lugar, que aquello que había sido pensado como Libro, sentido, espíritu, voz que alienta cuerpos mentados como poco más que meras ocasiones de su expresión, voz que luego narra -a los hechos como cuentas del rosario- , voz que como tal voz nunca muere; todo eso etéreo e inmortal -decimos- se muestra aquí en la imagen absolutamente terrena, corporal y transitoria de pelos entrelazados en un tocado histórico y como tal caduco: la trenza. En esta imagen resuena una risa y es una risa profana y desprovista de cinismo, que, a la vez que ríe, alberga, cuida, y da relevancia a un humildísimo fenómeno histórico: la práctica doméstica de trenzar los

\footnotetext{
${ }^{36}$ Fragmento de Benjamin extraído de La obra de los pasajes y citado por Pablo Oyarzún en "Cuatro señas sobre experiencia, historia y facticidad" en BENJAMIN, Walter. La dialéctica en suspenso. Santiago de Chile: ARCIS-LOM, 1996, p. 19.

37 "La fuerza de una carretera varía según se la recorra a pie o se la sobrevuele en aeroplano. Así también, la fuerza de un texto varía según sea leído o copiado. Quien vuela, sólo ve cómo la carretera va deslizándose por el paisaje y se desdevana ante sus ojos siguiendo las mismas leyes del terreno circundante. Tan sólo quien recorre a pie una carretera advierte su dominio y descubre cómo en ese mismo terreno, que para el aviador no es más que una llanura desplegada, la carretera, en cada una de sus curvas, va ordenando el despliegue de lejanías, miradores, calveros y perspectivas como la voz de mando de un oficial hace salir a los soldados de sus filas. Del mismo modo, sólo el texto copiado puede dar órdenes al alma de quien lo está trabajando, mientras que el simple lector jamás conocerá los nuevos paisajes que, dentro de él, va convocando el texto, esa carretera que atraviesa su cada vez más densa selva interior: porque el lector obedece al movimiento de su Yo en el libre espacio aéreo del ensueño, mientras que el copista deja que el texto le dé ordenes.” BENJAMIN, Walter. Calle de mano única. Madrid: Editora Nacional, 2002, p. 15 .

${ }^{38}$ BENJAMIN, Walter. "Apuntes sobre el concepto de historia" en La dialéctica en suspenso. Santiago de Chile: ARCIS-LOM, 1996, p. 78.
} 
cabellos. Pero, en su humildad y transitoriedad, esa imagen tiene, a su vez, el efecto corrosivo de la risa: no sólo arruina la pretensión de solemnidad de aquella figura de la historia como Libro y Voz, sino que la muestra precisamente como eso: una pretensión, que la risa desenmascara. Es a ese mostrar a lo que Benjamin llama "iluminar la realidad", iluminar profanamente la realidad.

Ahora bien, esas iluminaciones deben probar su potencia para arruinar la presunta dignidad de las grandes figuras, órdenes de justificación y pretensiones de eternidad, pero también -como señalábamos antes- para revelar lo trunco y pendiente de esas vidas-sidas. A ello apunta lo "deshilachado" de las "greñas" que "cuelgan" invocado por Benjamin en esta imagen. No se trata sólo de la "multiplicidad" de las fibras, de vidas cuya complejidad interna plantea una resistencia a las exigencias de la unidad que esta última sólo consigue vencer a través de la violencia identificadora; se trata de fibras cuyo carácter "deshilachado", "trunco", descompone la imagen de un sufrimiento ya superado, inactual, y, al hacerlo, muestra a una felicidad que supuestamente "tiene lugar" como algo no vigente aún. Por eso, de esas iluminaciones profanas se podría decir lo que Benjamin señala a propósito de la remembranza, es decir, que pueden convertir "lo inconcluso (la dicha) en algo concluido, y lo concluido (el sufrimiento) en algo inconcluso" 39 .

¿De qué modo se componen esas "iluminaciones"? Si la justificación ordena los acontecimientos como material inerte y dócil a la luz de un sentido visible como meta, la iluminación profana, que pretende hacerles justicia sin "justificarlos”, ¿no los aferra también como piezas de un orden alternativo? Sí y no, y en esa oscilación sobre el abismo de lo mismo se juega la singularidad de la "justicia interpretativa" benjaminiana. Detengámonos entonces brevemente en este último problema que atañe, también, a la

\footnotetext{
${ }^{39}$ BENJAMIN, Walter. “ 'Convoluto N' de La Obra de los pasajes ” en La dialéctica en suspenso. Santiago de Chile: ARCIS-LOM, 1996, p. 141.
} 
peculiaridad de los fenómenos que pueden constituirse en objeto de la "justicia interpretativa".

\section{4- Conocimiento materialista e iluminación profana}

En La obra de los pasajes, contestando al principio dominante de la continuidad pero también a esa primacía de la voz en la Filosofía de la Historia a la que aludíamos más arriba, Benjamin refiere a su método como "montaje literario", y agrega:

"Yo no tengo nada que decir. Sólo que mostrar. No voy a hurtar nada valioso ni me apropiaré de formulaciones ingeniosas. Pero los andrajos, los desechos: esos no los voy a inventariar, sino hacerles justicia del único modo posible: usándolos. ${ }^{, 40}$

Como suele enfatizar la interpretación contemporánea que, en las reflexiones benjaminianas, percibe ante todo un llamado a "leer la historia a contrapelo", la diferencia específica de esta lectura parecería definirse aquí en función de los materiales escogidos; materiales que, en este caso, serían precisamente aquellos descartados por la Gran Historia: sus desechos. Pero lo que con este énfasis la historiografía contemporánea que lo reivindica como modelo a veces pasa por alto, es lo inutilizable que -en el caso de Benjamin- resulta aquello mentado aquí a título de "inventario", en tanto método particular de lectura y configuración.

$\mathrm{Y}$ es que, como sugeríamos al principio a propósito de la lengua de la ciencia o del derecho en "Para una crítica de la violencia", Benjamin concibe al inventario como ese procedimiento que, en pos de su propia perpetuación, siempre tiene que poder ubicar los cuerpos, los sentidos, las materialidades, en su lugar; o, mejor dicho, como ese procedimiento que, puesto que para seguir existiendo como tal procedimiento, siempre tiene que poder ubicar los cuerpos en su lugar, tiene que tratarlos como conclusos, idénticos a sí mismos y aferrables como datos positivos, provenientes del único orden de realidad posible: el de las materialidades disponibles por la razón y los objetos adecuados de -y a- la conciencia ordenadora. La negativa

\footnotetext{
${ }^{40}$ BENJAMIN, Walter. “ 'Convoluto N' de La Obra de los pasajes ” en La dialéctica en suspenso. Santiago de Chile: ARCIS-LOM, 1996, pp. 117 y 118.
} 
a "tratar a los hechos como algo que se deja narrar" constituye aquí, por el contrario, un señalamiento de lo "inadecuados", lo "ajenos", que resultan esos hechos en relación a la conciencia narrativa. Ellos no son simplemente reconocibles como portadores de otro sentido, o de un sentido más amplio que incluiría más que el anterior, sino que distorsionan esa lengua tramada en las nociones de "portación”, "apropiación”, y "ubicación” del sentido.

Así, si es cierto que los materiales tratados por Benjamin como objetos de interpretación a menudo se diferencian de los privilegiados por la historiografía y la hermenéutica tradicional, lo hacen ante todo en tanto provenientes de otro orden de percepción y no de la misma percepción ampliada. Dicho de otro modo, como en el caso de los que aborda el psicoanálisis, se trata de objetos que saltan de $-\mathrm{y}$ hacen saltar a- "la ancha corriente de lo percibido" 41 para salirle al paso a la conciencia, como esa “escoria” de la que hablaba Freud, y que sin ser ajena a la significación no "le pertenecía" al sentido conciente o, para decirlo en términos de Benjamin, no era "tramada" por la conciencia. Y es por ello, precisamente, que en los textos benjaminianos, aún lo que no es una conciencia intencional: los muertos, los objetos domésticos, los edificios y los muebles, "hablan" y hacen reclamos. En ese "hablar" que, indudablemente, no podría ser un habla en sentido tradicional, aparece no obstante, para Benjamin, algo del orden de la verdad que no tiene su origen en la intención subjetiva sino "a

\footnotetext{
${ }^{41}$ Sobre la relación de los "objetos benjaminianos" con los del psicoanálisis, vale la pena recordar aquí un pasaje del famoso texto referido a las potencialidades disruptivas del cine: "El cine ha enriquecido nuestro mundo perceptivo con métodos que de hecho se explicarían por los de la teoría freudiana. Un lapsus en la conversación pasaba hace cincuenta años más o menos desapercibido [...] Pero todo ha cambiado desde la Psicopatología de la vida cotidiana. Esta ha aislado cosas (y las ha hecho analizables), que antes nadaban inadvertidas en la ancha corriente de lo percibido [...] En una ampliación no sólo se trata de aclarar lo que de otra manera no se vería claro, sino que aparecen en ella formaciones estructurales del todo nuevas [...] Así es como resulta perceptible que la naturaleza que habla a la cámara no es la misma que la que habla al ojo. Es sobre todo distinta porque en lugar de un espacio que trama el hombre con su conciencia presenta otro tramado inconcientemente." BENJAMIN, Walter. "La obra de arte en la época de la reproductibilidad técnica", en Discursos interrumpidos. Buenos Aires: Planeta Agostini, 1994, pp. 46-48. (Itálicas en el original)
} 
pesar" de ella. ${ }^{42}$ ¿Qué aparece? ¿Sobre qué llama nuestra atención la escoria? No sólo sobre aquello que prioritariamente tendemos a inventariar, sino sobre "lo más familiar": el inventario mismo. Lo "inconciente", dicho de otro modo, no son sólo los contenidos reprimidos sino fundamentalmente lo que hacemos con ellos, y la "iluminación profana" no es la que hace otro inventario con los desechos de la Gran Historia (el inventario de la "contrahistoria", por ejemplo) sino la que ilumina a esa Gran Historia prolongándose en el hecho de inventariar.

Pero entonces, ese tema del reconocimiento, de la familiaridad y -en contraste con ellos- el de lo ajeno, el de lo que no "nos pertenece", llama la atención sobre otra dimensión fundamental de la construcción benjaminiana de "iluminaciones profanas": a diferencia de las reconstrucciones elaboradas a partir de una empatía con los hechos, esa construcción implica, en primer lugar, la destrucción ${ }^{43}$; negándose a ofrecernos, en segundo lugar, una imagen positiva final con la cual identificarnos. Dicho de otro modo, mientras en la "justificación” los hechos se nos parecen en tanto eslabones de la misma cadena que conduce al presente, y en la exigencia historicista de captarlos "tal cual fueron" gracias a la "castidad del historiador", se anula -junto con las "perturbaciones exteriores"- toda distancia entre ellos y nosotros, las construcciones benjaminianas interrumpen cualquier empatía posible. Si ellas no excluyen algo del orden del "contacto", éste no se articulará al modo de lo idéntico o de lo que pertenece al mismo tronco, sino de lo que solamente y por un brevísimo instante apenas se "roza". O bien: esas construcciones nos recuerdan el estremecimiento fugaz que a veces experimentamos cuando nos sentimos aludidos por un dolor que sabíamos infinitamente lejano a nosotros, o por una felicidad súbita y desconocida en la que la faz del mundo aparece instantáneamente trastocada para dejarnos

\footnotetext{
42 "La verdad -escribe Benjamin en la introducción al texto sobre el Trauerspiel- es la muerte de la intención." BENJAMIN, Walter. El origen del drama barroco alemán. Madrid: Taurus, 1990, p. 18.

43 "Para el historiador materialista es importante diferenciar de la manera más estricta entre la construcción de un estado de cosas histórico y aquello que habitualmente se llama su 'reconstrucción'. La 'reconstrucción' en la empatía es de un solo estrato. La 'construcción' supone la 'destrucción'.” BENJAMIN, Walter. “ 'Convoluto N' de La obra de los pasajes”, en La dialéctica en suspenso. Santiago de Chile: ARCIS-LOM, 1996, p. 138
} 
con la sensación -pero en general sólo eso- de que entendimos algo. Y esas construcciones interrumpen cualquier empatía posible negándose a ofrecernos, en reemplazo de la anterior, otra imagen $-\mathrm{y}$, finalmente, $a$ la imagen- como punto final con el cual identificarnos, porque el método constructivo-destructivo benjaminiano "hace saltar" 44 y vuelve a "partir" los términos una y otra vez. ${ }^{45}$

Así, la iluminación profana, que pretende "hacer justicia" sin "justificar" la realidad ni ofrecerla, en la imagen, como objeto de identificación, trabaja sin duda- con piezas que reordena en composiciones alternativas. Pero con esta "composición" no sólo ha cambiado el estatuto tradicional de una imagen que pasa a ser ahora concebida como un inestable campo de fuerzas en tensión ${ }^{46}$, sino que ha mutado también la constitución interna de las piezas, arrancadas del "Texto" de la historia antes que encontradas en la escritura $^{47}$, y "afiladas" por el intérprete como algo que, en lugar de

\footnotetext{
44 "El momento destructivo o crítico en la historiografía materialista entra en vigencia al ser hecha saltar la continuidad histórica, con la cual se constituye por primera vez el objeto histórico [...] La historiografía materialista escoge sus objetos sin mano débil. No los aferra, sino que los hace saltar del curso." BENJAMIN, Walter. " 'Convoluto N' de La obra de los pasajes", en La dialéctica en suspenso. Santiago de Chile: ARCIS-LOM, 1996, p. 149.

45 "Es muy fácil -dice Benjamin- emprender para cada época, en sus diversos 'dominios', divisiones, de tal suerte que a un lado esté la parte 'fructífera', 'pletórica de porvenir', 'positiva' de esta época, y al otro la parte desechable, retrógrada, fenecida. Pero toda negación tiene su valor únicamente como fondo para los contornos de lo viviente, lo positivo. Por eso es de importancia decisiva aplicar de nuevo a esta parte ya descartada, negativa, una división tal que con un desplazamiento del punto de mira comparezca también en ella, de nuevo, algo positivo y distinto al anteriormente señalado." BENJAMIN, Walter. " 'Convoluto N' de La obra de los pasajes", en La dialéctica en suspenso. Santiago de Chile: ARCIS-LOM, 1996, p. 115.

${ }^{46}$ Benjamin piensa esta mutación de la imagen a través de la diferencia que establece entre "imagen arcaica" e "imagen dialéctica". La segunda, que constituye "el objeto mismo construido en la exposición materialista de la historia" ("Convoluto N de la Obra de los pasajes", en La dialéctica en suspenso. Santiago de Chile: ARCIS-LOM, 1996, p. 150), rechaza la estabilidad y permanencia de la imagen especular: "es una imagen relampagueante. Así, como una imagen que relampaguea en el ahora de la congnoscibilidad, ha de aferrarse firmemente lo sido. El salvamento que de esa suerte -y sólo de esa suerte- se lleva a cabo, sólo se deja cumplir en aquello que al instante que sigue se ha perdido ya irrescatablemente." BENJAMIN, Walter. " 'Convoluto N' de La obra de los pasajes", en La dialéctica en suspenso. Santiago de Chile: ARCIS-LOM, 1996, p. 145. 47 "Si se quiere considerar la historia como un texto, vale a su propósito lo que un autor reciente dice acerca de los textos literarios: el pasado ha depositado en ello imágenes que se podría comparar a las que son fijadas por una plancha fotosensible: sólo el futuro tiene desarrolladores a su disposición, que son lo bastante fuertes como para hacer que la imagen salga a la luz con todos los detalles [...] Leer lo que nunca fue escrito [...] el lector en que ha de pensarse aquí es el verdadero historiador." BENJAMIN, Walter. "Apuntes sobre el
} 
presentar la docilidad y manejabilidad de un mero material inerte, "corta", hace "tajos" en el presente y en la conciencia actual. ${ }^{48}$ Piezas semejantes no pueden ser tocadas sin precauciones, y mucho menos pueden ser poseídas. La lectura que intenta "hacer justicia" no lo pretende, y no postula tampoco a esa justicia como algo "finalmente" asequible.

Antes que algo que se puede o se debería alcanzar, la justicia aparece aquí como algo que es preciso hacer: se hace justicia, y se hace frente a una violencia actual. Dicho de otro modo, la justicia no constituye algo que se pueda afirmar positivamente ni en su definición (al modo del enunciado la justicia es: ...), ni en sus condiciones ( $s i$ se dan tales condiciones, entonces hay justicia), sino una noción crítica que se enuncia cuando "ha habido violencia”, y, a la inversa, cuya enunciación llama nuestra atención sobre el hecho de que allí donde todo parecería armoniosa comunicación, la violencia "ha tenido lugar". Pero, si como hemos intentado sugerir, justicia y felicidad se encuentran entrelazadas, en ese llamado a "hacer justicia" no hay pura negatividad sino que late una potencia, el deseo de una dicha posible de la cual, también, nos "hablan" las imágenes expuestas en la iluminación profana. Hay, dicho de otro modo, un llamado a despertar del sueño, pero no sólo a despertar de, a interrumpir, el "sueño feliz" para ser más realistas, sino también -y sobre todo- a interrumpir el sueño del sacrificio como destino para poder empezar a atender colectivamente a las instantáneas de felicidad que atraviesen el horizonte del presente que nos tocó vivir. Atenderlas para poder interpretarlas en su doble sentido de chance (de ruptura) y tarea (de construcción).

\section{REFERENCIAS}

concepto de historia" en La dialéctica en suspenso. Santiago de Chile: ARCIS-LOM, 1996, p. 86.

48 “¿Por qué vía es posible unir una intuibilidad acrecentada con la ejecución del método marxista? La primera etapa de este camino será acoger el principio del montaje en la historia. Erigir, entonces, las grandes construcciones a partir de las más pequeñas piezas de construcción, confeccionadas de manera cortante y tajante." BENJAMIN, Walter. "Apuntes sobre el concepto de historia" en La dialéctica en suspenso. Santiago de Chile: ARCISLOM, 1996, p. 119. 
ADORNO, Theodor. Minima Moralia. Madrid: Editora Nacional, 2002. Traducción de Joaquín Chamorro Mielke.

BENJAMIN, Walter. La dialéctica en suspenso. Santiago de Chile: ARCIS-LOM, 1996. Traducción de Pablo Oyarzún.

BENJAMIN, Walter. "El surrealismo. La última instantánea de la inteligencia europea" en Iluminaciones I. Madrid: Taurus, 1980. Traducción de Jesús Aguirre.

BENJAMIN, Walter. Iluminaciones IV. Madrid: Taurus, 1998. Traducción de Roberto Blatt.

BENJAMIN, Walter. Para una crítica de la violencia. Santiago de Chile: Metales pesados, 2008. Traducción de Pablo Oyarzún

BENJAMIN, Walter. El origen del drama barroco alemán. Madrid: Taurus, 1990. Traducción de José Muñoz Millanes.

BENJAMIN, Walter. Calle de mano única. Madrid: Editora Nacional, 2002. Traducción de Juan J. del Solar y Mercedes Allende Salazar.

BENJAMIN, Walter. "La obra de arte en la época de la reproductibilidad técnica", en Discursos interrumpidos. Buenos Aires: Planeta Agostini, 1994. Traducción de Jesús Aguirre.

COLLINGWOOD-SELBY, Elizabeth. Walter Benjamin. La lengua del exilio. Santiago de Chile: ARCIS-LOM, 1997

HEGEL, Georg Wilhelm Friedrich. Lecciones sobre la Filosofía de la Historia Universal. Madrid: Alianza, 1999. Traducción de José Gaos. 
HERDER, Johann Gottfried. Ideas para una Filosofía de la Historia de la Humanidad. Buenos Aires: Losada, 1959. Traducción de Rovira Armengol.

LEVI-STRAUSS, Claude. "Historia y etnología” en Antropología estructural. Buenos Aires: EUDEBA, 1977. Traducción de Eliseo Verón.

LÓPEZ, María Pía. "Minimalismo de la conversación" en Revista Nombres, N²4, Año XIX, Universidad Nacional de Córdoba.

LUKÁCS, George. Historia y conciencia de clase. Madrid: Orbis, 1985. Traducción de Manuel Sacristán.

OYARZÚN ROBLES, Pablo. "Cuatro señas sobre experiencia, historia y facticidad", en La dialéctica en suspenso. Santiago de Chile: ARCISLOM, 1996.

SCHWARZBÖCK, Silvia. Adorno y lo político. Buenos Aires: Prometeo, 2008. 